\title{
Rheological and dielectric properties of different gold nanoparticle sizes
}

Mohamed Anwar K Abdelhalim*, Mohsen M Mady ${ }^{1,2}$ and Magdy M Ghannam

\begin{abstract}
Background: Gold nanoparticles (GNPs) have found themselves useful for diagnostic, drug delivery and biomedicine applications, but one of the important concerns is about their safety in clinical applications. Nanoparticle size has been shown to be an extremely important parameter affecting the nanoparticle uptake and cellular internalization. The rheological properties assume to be very important as it affects the pressure drop and hence the pumping power when nano-fluids are circulated in a closed loop. The rheological and dielectric properties have not been documented and identified before. The aim of the present study was to investigate the rheology and the dielectric properties of different GNPs sizes in aqueous solution.

Methods: 10, 20 and $50 \mathrm{~nm}$ GNPs (Product MKN-Au, CANADA) was used in this study. The rheological parameters were viscosity, torque, shear stress, shear rate, plastic viscosity, yield stress, consistency index, and activation energy. These rheological parameters were measured using Brookfield LVDV-III Programmable rheometer supplied with temperature bath and controlled by a computer.

Results: The shear stress and shear rate of GNPs have shown a linear relationship and GNPs exhibited Newtonian behaviour. The GNPs with larger particle size $(50 \mathrm{~nm})$ exhibited more viscosity than those with smaller particle sizes (10 and $20 \mathrm{~nm}$ ). Viscosity decreased with increasing the temperature for all the examined GNP sizes. The flow behaviour index $(n)$ values were nearly $\leq 1$ for all examined GNP sizes. Dielectric data indicated that the GNPs have strong dielectric dispersion in the frequency range of $20-100 \mathrm{kHz}$. The conductivity and relaxation time decreased with increasing the GNP size.

Conclusions: This study indicates that the GNP size has considerable influence on the viscosity of GNPs. The strong dielectric dispersion was GNP size dependent. The decrease in relaxation time might be attributed to increase in the localized charges distribution within the medium confirmed by the conductivity data. This study suggests that further experiments are required to be done after the administration of GNPs through different routes in rats in vivo.
\end{abstract}

Keywords: Gold nanoparticles, rheological parameters, size, temperature, dielectric, conductivity

\section{Introduction}

Nanotechnology is enabling technology that deals with nano-meter sized objects. A study on nanoparticle is becoming a hot point owing to their novel physical and chemical attributes in electronics [1-4], optics [1,5], electro-magnetic [6]. More interests are drawn to the particular optical characteristics of nanoparticles (NPs) such as surface plasmon resonance (SPR) [7], plasmon absorption (PA) [8], surface enhanced Raman scattering

\footnotetext{
* Correspondence: abdelhalimmak@yahoo.com

'Department of Physics and Astronomy, College of Science, King Saud

University, P.O. 2455, Riyadth 11451, Saudi Arabia

Full list of author information is available at the end of the article
}

[9] and resonance Rayleigh scattering [10]. These studies are very important not only for knowing about the new optical properties but also for studying the characterization and detection methods of nanoparticles.

The GNPs have unique optical properties such as distinctive extinction bands in the visible region, due to surface plasmon oscillation of free electrons [11]. The physical origin of the light absorption by GNPs is the coherent oscillation of the conduction band electrons induced by the interacting electromagnetic field. The absorption band results when the incident photon frequency is resonant with the collective oscillation of the

\section{Biomed Central}


conduction band electrons and is known as the surface plasmon resonance (SPR). The resonance frequency of this SPR is strongly dependent upon the size, shape, dielectric properties, and local environment of the nanoparticles [12-17]. This is attributable to electric dipoledipole interaction and coupling between plasmons of neighboring particles in the dispersion.

SPR property allows the use of GNPs for many applications in the bioscience and medical fields. The GNPs are used as immunostaining marker particles for electron microscopy, and as chromophores for immunoreactions and nucleic acid hybridization [18,19]. Their application for gene delivery into cells was reported [20-23]. In addition, GNPs have attracted much attention as photo-thermal agents in hyperthermia [24].

Owing to the unique optoelectronic properties with their controlled size and morphology, GNPs find significance in the field of bionanotechnology [24] as biomarkers [25], biosensors [26], cancer diagnostic [27] and vehicles for drug delivery [24].

The size of nanomaterials is similar to that of most biological molecules; therefore, nanomaterials can be useful for both in vivo and in vitro biomedical research and applications. Therefore, an increased attention is focused on the applications of nanoparticles in biology and medicine. Therefore, it is significant for extending the characterization methods and new applications of GNPs to further study their other optical properties.

The release of drug from semi-solid carriers is influenced by the rheological behaviour as well. The effect of certain parameters such as storage time, and temperature on the quality of GNPs as pharmaceutical products can be also investigated via rheological measurements. Rheological analysis can be employed as a sensitive tool in predicting the physical properties of the GNPs sizes.

Over the past few years, dielectric properties of different NPs have been extensively investigated to get attractive information about the localized surface plasmons, and their local dielectric environment [24-28].

The objective of the present experimental work is to explore the effects of the GNP size on the rheological properties of GNPs at a fixed temperature of $37{ }^{\circ} \mathrm{C}$ and over a temperature range from $37{ }^{\circ} \mathrm{C}$ to $42{ }^{\circ} \mathrm{C}$. In addition to investigate the electrical permittivity $\left(\varepsilon^{\prime}\right)$, conductivity $(\sigma)$ and loss factor $(\tan \delta$ ) for 10,20 and $50 \mathrm{~nm}$ GNPs in the frequency range of $20 \mathrm{~Hz}$ to $100 \mathrm{kHz}$ at room temperature.

\section{Materials and methods \\ Gold nanoparticles size}

Different GNPs sizes were purchased (Product MKN-Au) and used in this study. The GNPs sizes were in aqueous solution of size $10 \mathrm{~nm}$ (Product MKN-Au-010; concentration $0.01 \% \mathrm{Au}$ ), GNPs of size $20 \mathrm{~nm}$ (Product MKN-
Au-020; concentration $0.01 \% \mathrm{Au}$ ), and GNPs of size 50 nm (Product MKN-Au-050; concentration 0.01\% Au).

\section{Experimental set up and rheological parameters}

The experimental setup for measurement of several rheological parameters of GNPs with different particle sizes $(10,20$ and $50 \mathrm{~nm})$. The rheological parameters were viscosity, torque, shear stress, shear rate, plastic viscosity, yield stress, consistency index, and activation energy. These rheological parameters were measured using Brookfield LVDV-III Programmable rheometer (cone-plate viscometer; Brookfield Engineering Laboratory, Incorporation, Middleboro, USA, supplied with temperature bath controlled by a computer. The rheometer was guaranteed to be accurate within $\pm 1 \%$ of the full scale range of the spindle/speed combination in use reproducibility is within $\pm .2 \%$.

Rheological parameters were measured at started temperature of $37^{\circ} \mathrm{C}$ and at a gradually increase of temperature to $42^{\circ} \mathrm{C}$. Temperature inside the sample chamber was carefully monitored using a temperature sensor during the viscosity measurements.

A cone and plate sensor having a diameter of $2.4 \mathrm{~cm}$ with an angle of 0.8 was used. The rheometer was calibrated using the standard fluids. This viscometer has a viscosity measurement range of 1.5-30,000 $\mathrm{mPas}$ and can handle the viscosity measurement results within the temperature range of this experiment.

The spindle type (SC-40) and its speed combinations will produce results with high accuracy when the applied torque is in the range of $10 \%$ to $100 \%$ and accordingly the spindle is chosen.

$0.5 \mathrm{ml}$ of each GNP size in aqueous solution was poured in the sample chamber of the rheometer. The spindle was immersed and rotated in these gold nanofluids in the speed range from 50 to 250 RPM in steps of 20 minutes. The viscous drag of the GNP aqueous solution against the spindle was measured by the deflection of the calibrated spring.

\section{Plastic viscosity and yield stress}

The flow curves were plotted between shear stress $\left(\right.$ dyne $\left./ \mathrm{cm}^{2}\right)$ and shear rate $\left(\mathrm{s}^{-1}\right)$ for each gold nanoparticle size. Plastic viscosity and yield stress were calculated from the linear fitting of the flow curves [29,30].

\section{The flow activation energy}

The effect of temperature on the gold nanofluids viscosity has been described by the Arrhenius type equation [29]:

$$
\eta=\eta e^{(\mathrm{Ea} / \mathrm{RT})}
$$

Where $\eta$ is the viscosity, $\eta_{0}$ is the viscosity at reference temperature, $E_{a}$ is the flow activation energy, $R$ is 
the universal gas constant, and $\mathrm{T}$ is the absolute temperature. The $E_{a}$ for the flow was determined for 10,20 and $50 \mathrm{~nm}$ GNPs.

\section{The electrical parameters}

The electrical parameters were measured in the frequency range of $20 \mathrm{~Hz}$ up to $1 \mathrm{MHz}$ using a WAYNE KERR precision component analyzer, model $6440 \mathrm{~B}$ (UK). The sample cell has two squared platinum black electrodes each having an area of $1 \times 1 \mathrm{~cm}^{2}$ with an inner electrode distance of $1 \mathrm{~cm}$. The measurements were performed at $20^{\circ} \mathrm{C}$. For a dielectric material placed between two parallel plate capacitor, the measured values of capacitance $(C)$ and resistance $(R)$ were used to calculate the real $\left(\varepsilon^{\prime}\right)$ and imaginary part $\left(\varepsilon^{\prime \prime}\right)$ of the complex permittivity $\varepsilon^{*}=\varepsilon^{\prime}-j \varepsilon "$, while conductivity $(\sigma)$ and the relaxation time $(\boldsymbol{\tau})$ were calculated using the following equations:

i) $\varepsilon^{\prime}=\varepsilon_{0} \mathrm{Ck} \mathrm{k}=\mathrm{lcm}^{-1}$

Where $k$, is the cell constant which depends on the cell dimensions

ii) Loss tangent $\tan \delta=\varepsilon^{\prime \prime} / \varepsilon^{\prime}=1 / 2 \pi f R C$ so, $\varepsilon^{\prime \prime}=\varepsilon^{\prime} \tan \delta$

iii) The conductivity $\sigma=k / R\left(\Omega^{-1} m^{-1}\right)$

iv) Relaxation time $\tau=1 / 2 \pi f_{c}$

$f_{c}$ is the critical frequency corresponding to the mid point of the dispersion curve. If any dielectric material is introduced between the two plates, the corresponding response to a sinusoidal field will be characterized by dielectric properties (dielectric permittivity $\varepsilon$, and conductivity $\sigma$ ) which vary with frequency. The charge and current densities induced in response to an applied electric field is an example of an idealized parallel plate.

\section{Results and discussion}

Size and morphology of different gold nanoparticles

The 10 and $20 \mathrm{~nm}$ GNPs show spherical morphology while $50 \mathrm{~nm}$ GNPs show hexagonal morphology, and with good particle size distribution dispersed in the solution (Figure 1).

The mean sizes for these GNPs were calculated from the images taken by the transmission electron microscope (TEM) for 10, 20 and $50 \mathrm{~nm}$ GNPs (Figure 2). Figure 2 shows that GNPs with mean size 9.45 $\pm 1.33 \mathrm{~nm}$ for GNPs size of $10 \mathrm{~nm} ; 20.18 \pm 1.80 \mathrm{~nm}$ for GNPs of size $20 \mathrm{~nm}$ and $50.73 \pm 3.58 \mathrm{~nm}$ for GNPs of size $50 \mathrm{~nm}$. The high electron densities of GNPs as well as the homogeneity of the particles shape and size make them highly conspicuous under the TEM. In addition, relatively simple methods can be used to obtain populations of GNPs of different average sizes, which allow simultaneous detection of several targets.

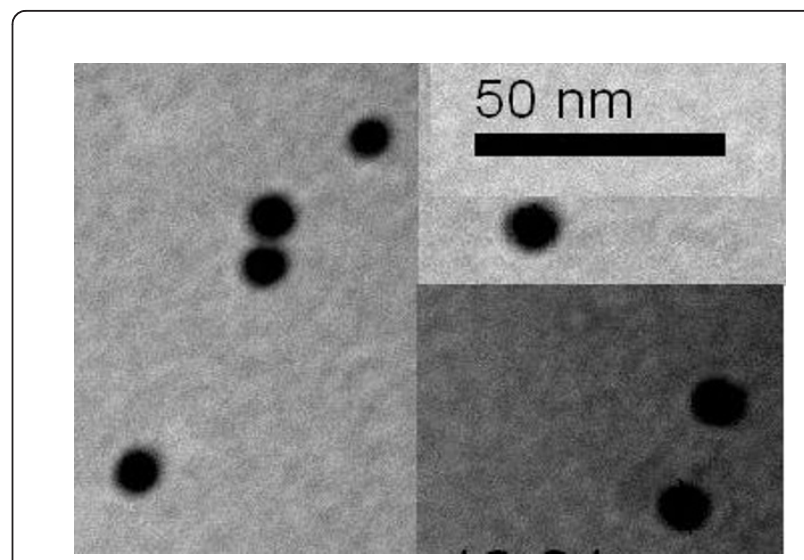

\section{$10 \mathrm{~nm}$}

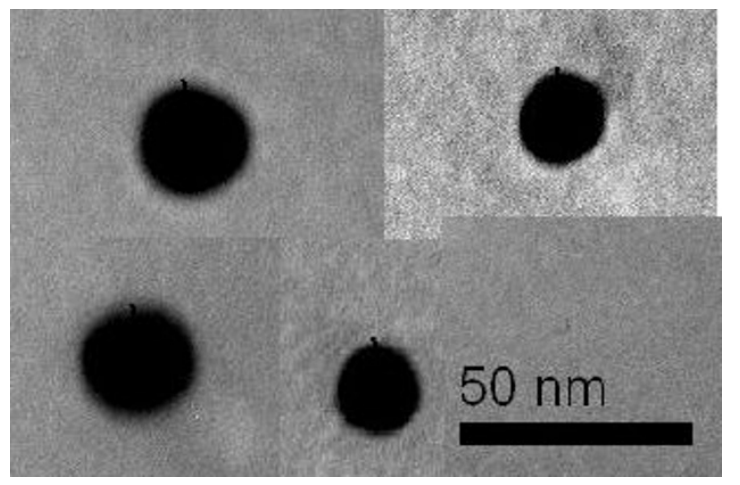

\section{$20 \mathrm{~nm}$}

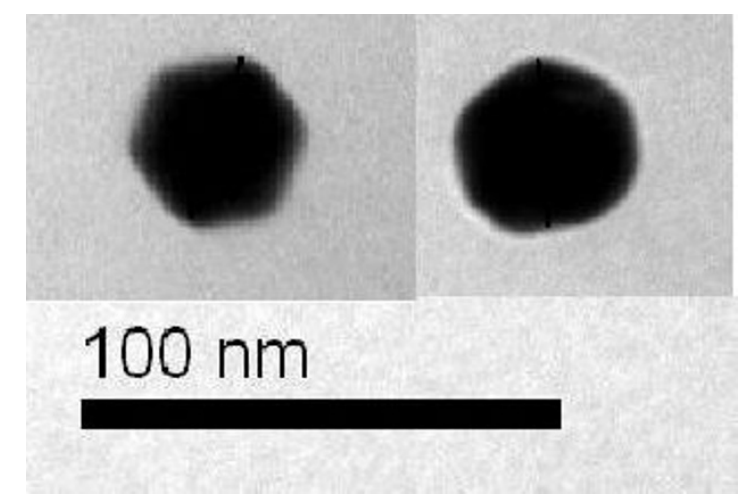

$50 \mathrm{~nm}$

Figure 1 TEM images for 10, 20 and $50 \mathrm{~nm}$ gold nanoparticle samples

Rheological parameters measurement

The rheological parameters of different GNPs sizes were measured. The relationship between shear stress and shear rate for different GNPs sizes at fixed temperature 


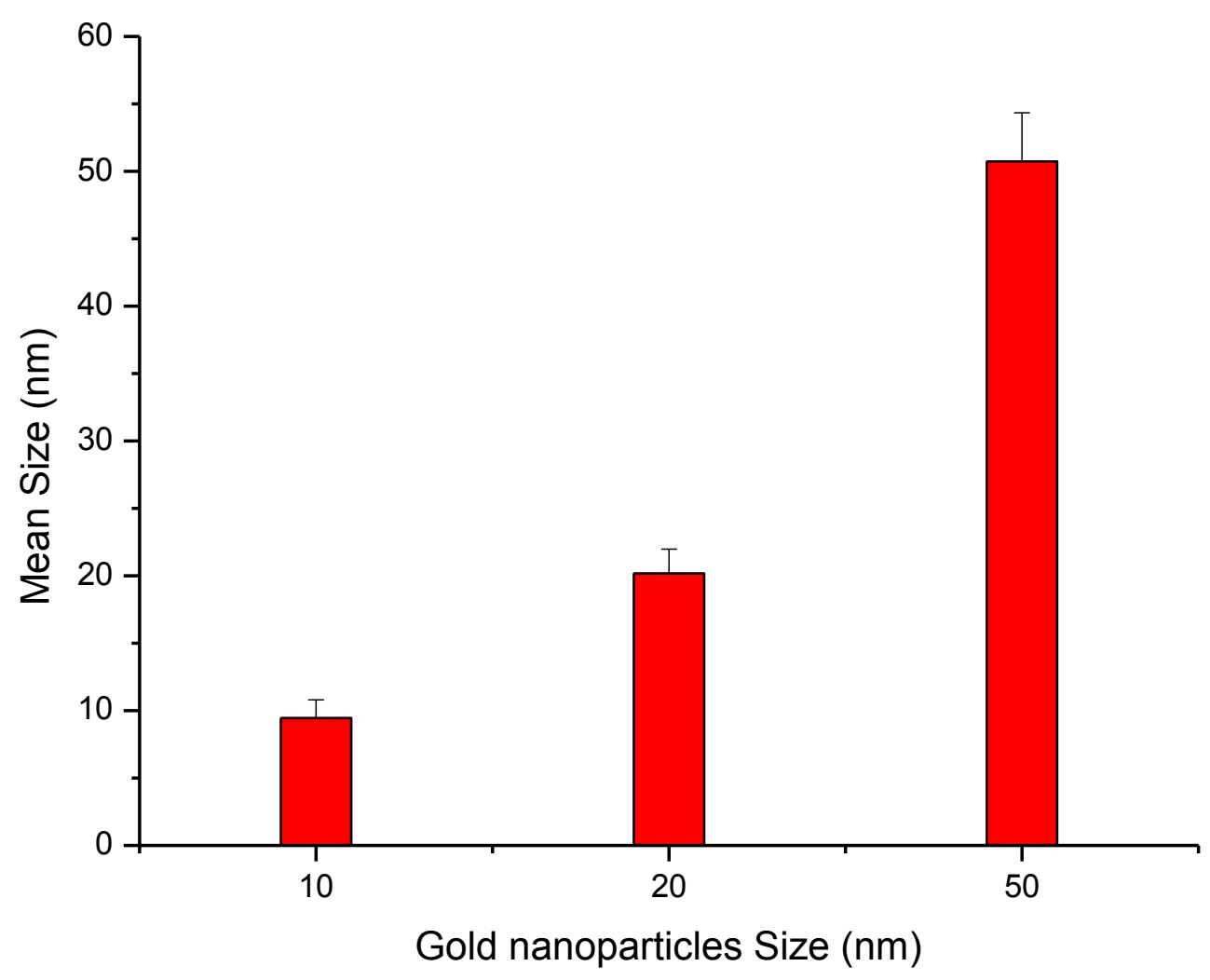

Figure 2 The size of 10, 20 and $50 \mathrm{~nm}$ gold nanoparticles.

of $37{ }^{\circ} \mathrm{C}$ was measured (Figure 3 ). The relationship between shear stress and shear rate for different GNPs sizes was linearly related, and GNPs were exhibited Newtonian behaviour. The linear flow rate relation for the different GNPs sizes were described by the following

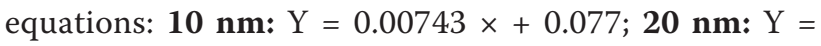
$0.00775 \times+0.104$ and $50 \mathbf{n m}: \mathrm{Y}=0.00793 \times+0.038$

The plastic viscosity (a measure of the internal resistance to fluid flow of a Bingham plastic, expressed as the tangential shear stress in excess of the yield stress divided by the resulting rate of shear) [29], yield stress (dyne $/ \mathrm{cm}^{2}$ ) (the minimum stress needed to cause a Bingham plastic to flow), consistency index $\mathrm{k}$ (an indication of the viscous nature of gold nanoparticles), the flow behaviour index (n) (a measure of departure from Newtonian flow) and activation energy $(\mathrm{kJ} / \mathrm{mol})$ were calculated for different GNPs sizes as shown in table 1.

These parameters were calculated from fitting the experimental data for the different GNPs sizes. $\mathrm{n}$ and $\mathrm{k}$ values were calculated from equation (1). The yield stress was increased from $0.038 \pm 0.048 \mathrm{dyne} / \mathrm{cm}^{2}$ for GNPs of size $50 \mathrm{~nm}$ to $0.104 \pm 0.030$ dyne $/ \mathrm{cm}^{2}$ for GNPs of size $20 \mathrm{~nm}$. While the plastic viscosity decreased from $0.793 \pm 0.003$ for GNPs of size $50 \mathrm{~nm}$ to $0.775 \pm 0.003$ for GNPs of size $20 \mathrm{~nm}$. The $\mathrm{n}$ and $\mathrm{k}$ values were ranged from $0.991 \pm 0.0026$ to $1.005 \pm$ 0.0040 , and from $0.846 \pm 0.017$ to $0.727 \pm 0.022$, respectively. The values of the flow behaviour index (n) were equal $\leq 1$ for all the different GNPs sizes.

The rheological properties for the different GNPs sizes in aqueous solution can be described by this power law model [30]:

$$
\mathrm{t}=\mathrm{k} \gamma^{\mathrm{n}}
$$

Where $\tau$ is the shear stress, $\mathrm{k}$ is the consistency index, $\gamma$ is the shear rate, and $n$ is the flow behaviour index. $\mathrm{k}$ can be used to describe the variation in plastic viscosity for the different GNPs sizes [30].

The mean viscosity measured for the different GNPs sizes at wide range of shear rate $\left(375-1875 \mathrm{~s}^{-1}\right.$ is shown in Figure 4. The mean viscosity measured for different GNPs sizes increased with increasing the GNP size. Based on the present results of GNPs rheological properties, it can be concluded that increase the size of GNPs would cause an increase in the GNPs viscosity.

The measured viscosity for all GNPs sizes has shown a decrease with increase in the nanoparticles temperatures $\left(37^{\circ} \mathrm{C}\right.$ to $42{ }^{\circ} \mathrm{C}$ ), as can be observed from Figure 5 . The GNPS with large size $(50 \mathrm{~nm})$ were exhibited higher viscosity. 


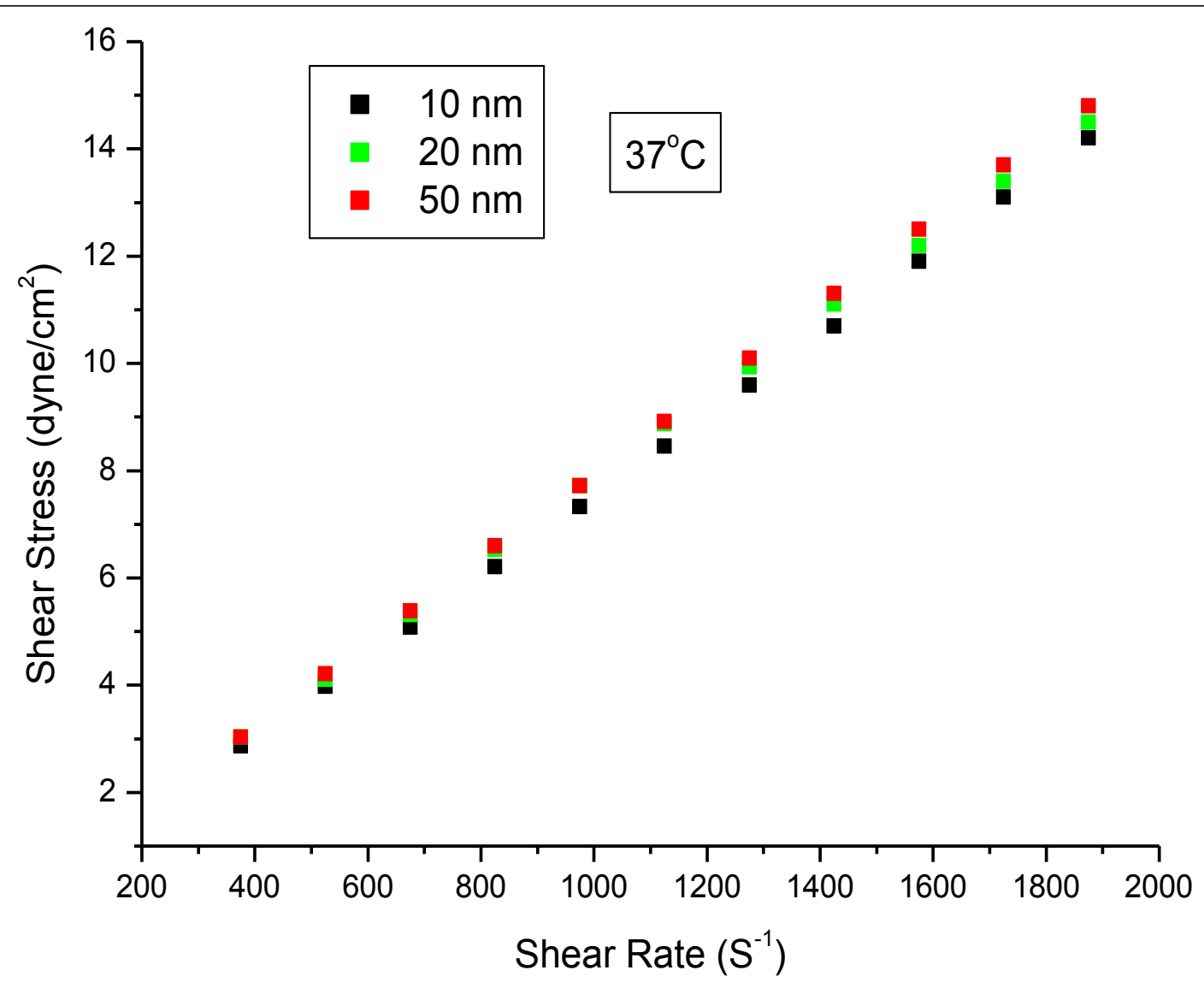

Figure 3 The relation between shear rate and shear stress for 10, 20 and $50 \mathrm{~nm}$ gold nanoparticle sizes at temperature of $37^{\circ} \mathrm{C}$

The viscosity of different GNPs sizes were not altered for different shear rates at fixed temperature of $37^{\circ} \mathrm{C}$ as shown in Figure 6.

\section{The dielectric Measurements}

Figures 7 and 8 show the variation of electrical permittivity $\left(\varepsilon^{\prime}\right)$ and conductivity $(\sigma)$ with frequency at room temperature for different GNPs sizes 10, 20 and $50 \mathrm{~nm}$. The presented dielectric data indicates that the GNPs have strong dielectric dispersion corresponding to the alpha relaxation region in the frequency range of $20 \mathrm{~Hz}$ to $100 \mathrm{kHz}$ which identified as anomalous frequency dispersion. A rapid decrease in the dielectric constant may be attributed to the tendency of dipoles in GNPs to orient themselves in the direction of the applied field in the low-frequency range. However, in the high-frequency range the dipoles will hardly be able to orient themselves in the direction of the applied field and hence the value of the dielectric constant is nearly constant. Moreover, the conductivity decreases as the size of GNPs increases. At high frequency, the conductivity increased rapidly for all the examined GNPs size.

The variation of loss factor $(\tan \delta)$ as a function of frequency for the different GNPs sizes is shown in Figure 9. It is clear that GNPs show a relaxation process. The relaxation time was found to decrease with the increase of GNPs size and was found to be 2.5, 3.5 and $4 \mathrm{~ms}$ for 10, 20 and $50 \mathrm{~nm}$ GNP size, respectively. This may be

Table 1

\begin{tabular}{llll}
\hline Gold nanoparticle size $(\mathbf{n m})$ & $\mathbf{1 0} \mathbf{n m}$ & $\mathbf{2 0} \mathbf{n m}$ & $\mathbf{5 0} \mathbf{n m}$ \\
\hline Plastic viscosity (cP) & $0.743 \pm 0.003$ & $0.775 \pm 0.003$ & $0.793 \pm 0.003$ \\
Yield stress (dyne/cm ${ }^{2}$ ) & $0.077 \pm 0.040$ & $0.104 \pm 0.030$ & $0.038 \pm 0.048$ \\
Consistency index (cP) (k) & $0.727 \pm 0.022$ & $0.92 \pm 0.029$ & $0.846 \pm 0.017$ \\
Flow index (n) & $1.005 \pm 0.0040$ & $0.997 \pm 0.0043$ & $0.991 \pm 0.0026$ \\
Activation Energy (kJ/mol) & 332.55 & 415.40 & 182.20 \\
\hline
\end{tabular}




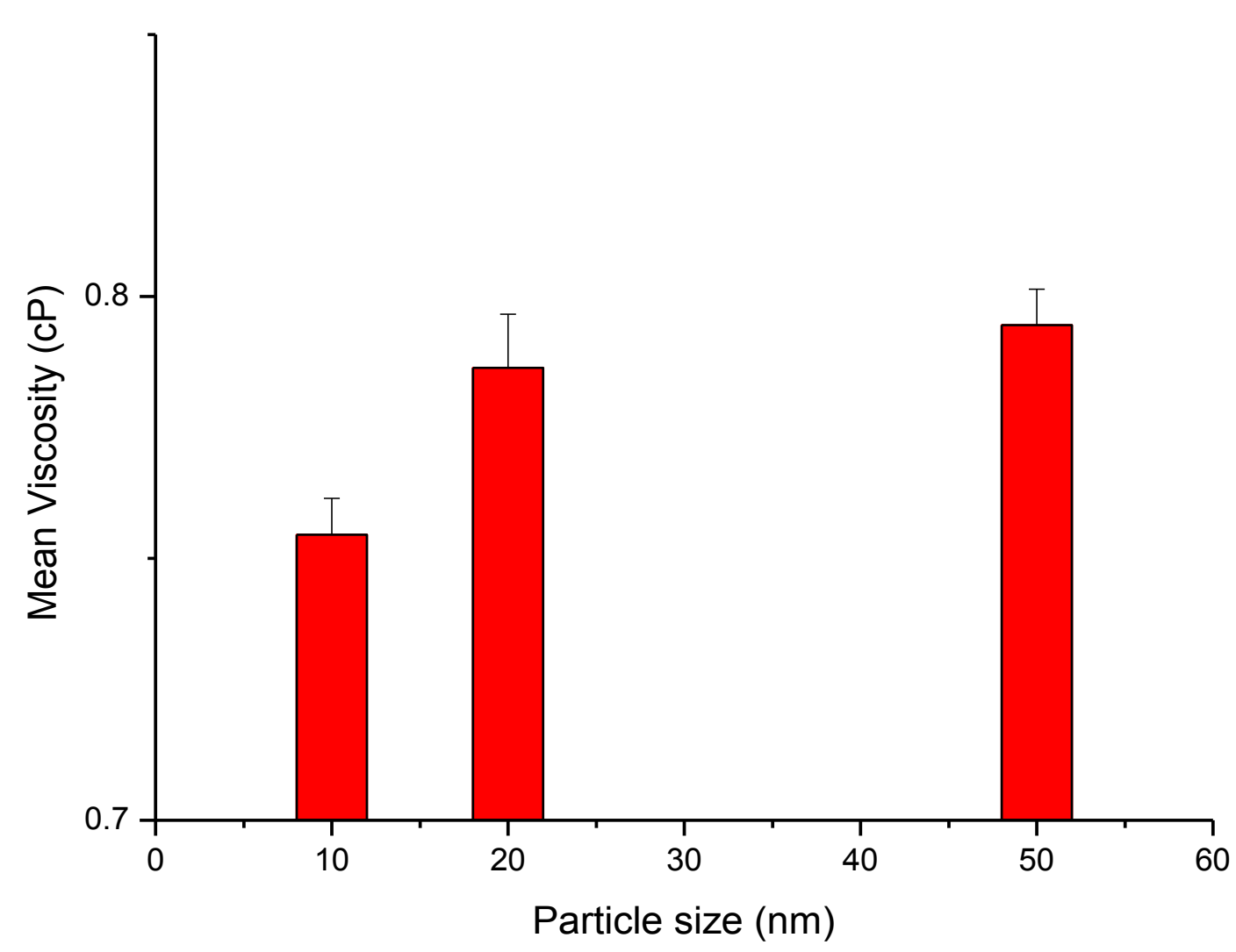

Figure 4 variation of mean viscosity for 10,20 and $50 \mathrm{~nm}$ gold nanoparticles.

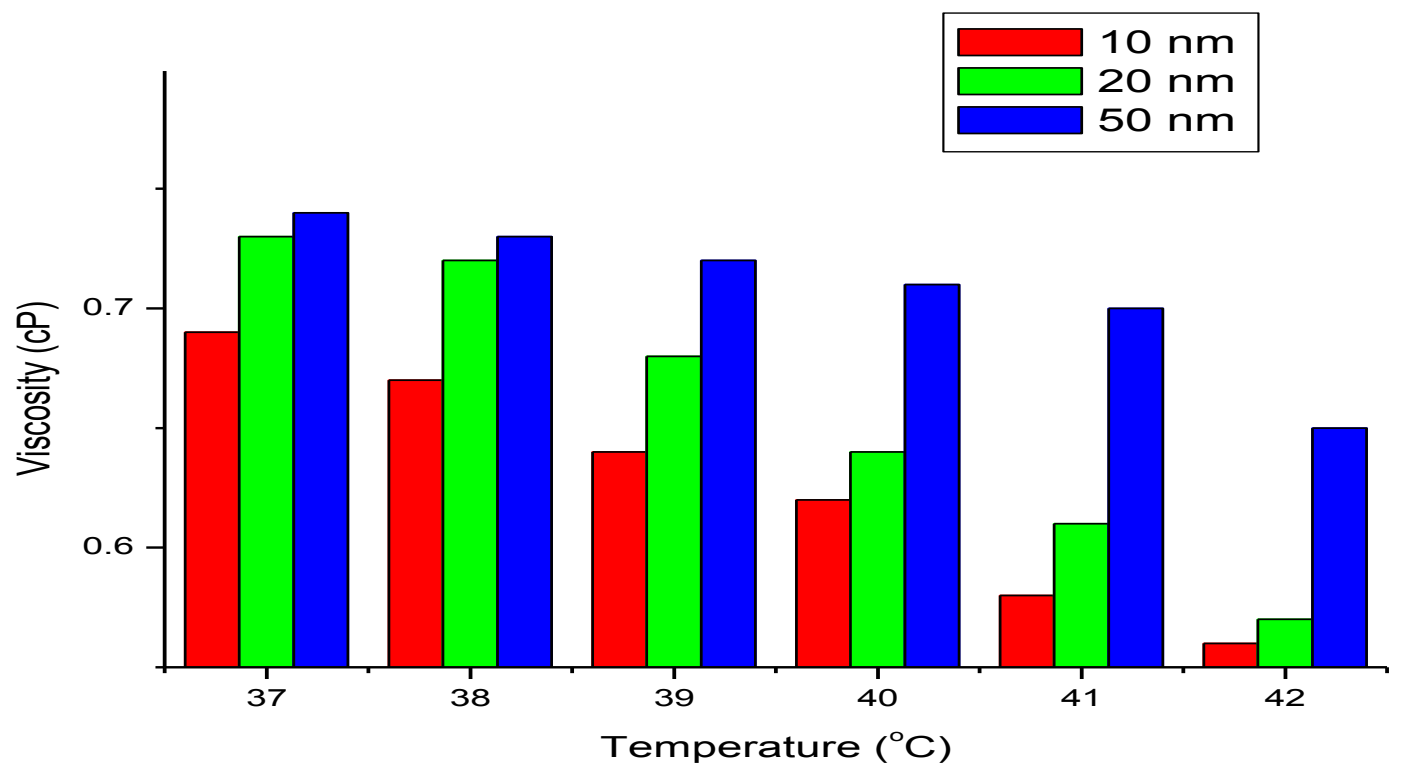

Figure 5 variation of viscosity for 10, 20 and $50 \mathrm{~nm}$ gold nanoparticles versus the temperature. 


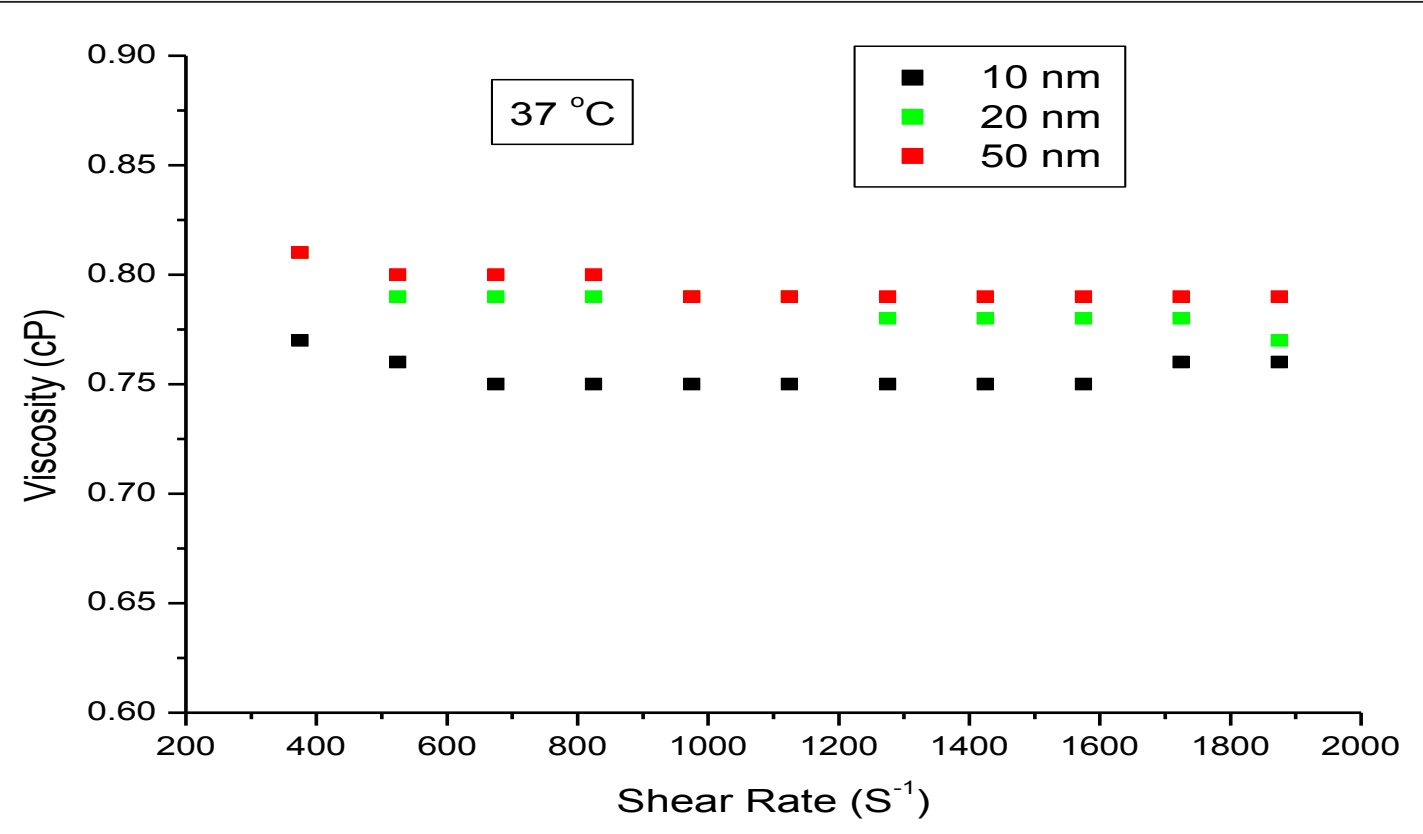

Figure 6 variation of the viscosity with shear rate for 10, 20 and $50 \mathrm{~nm}$ gold nanoparticles.

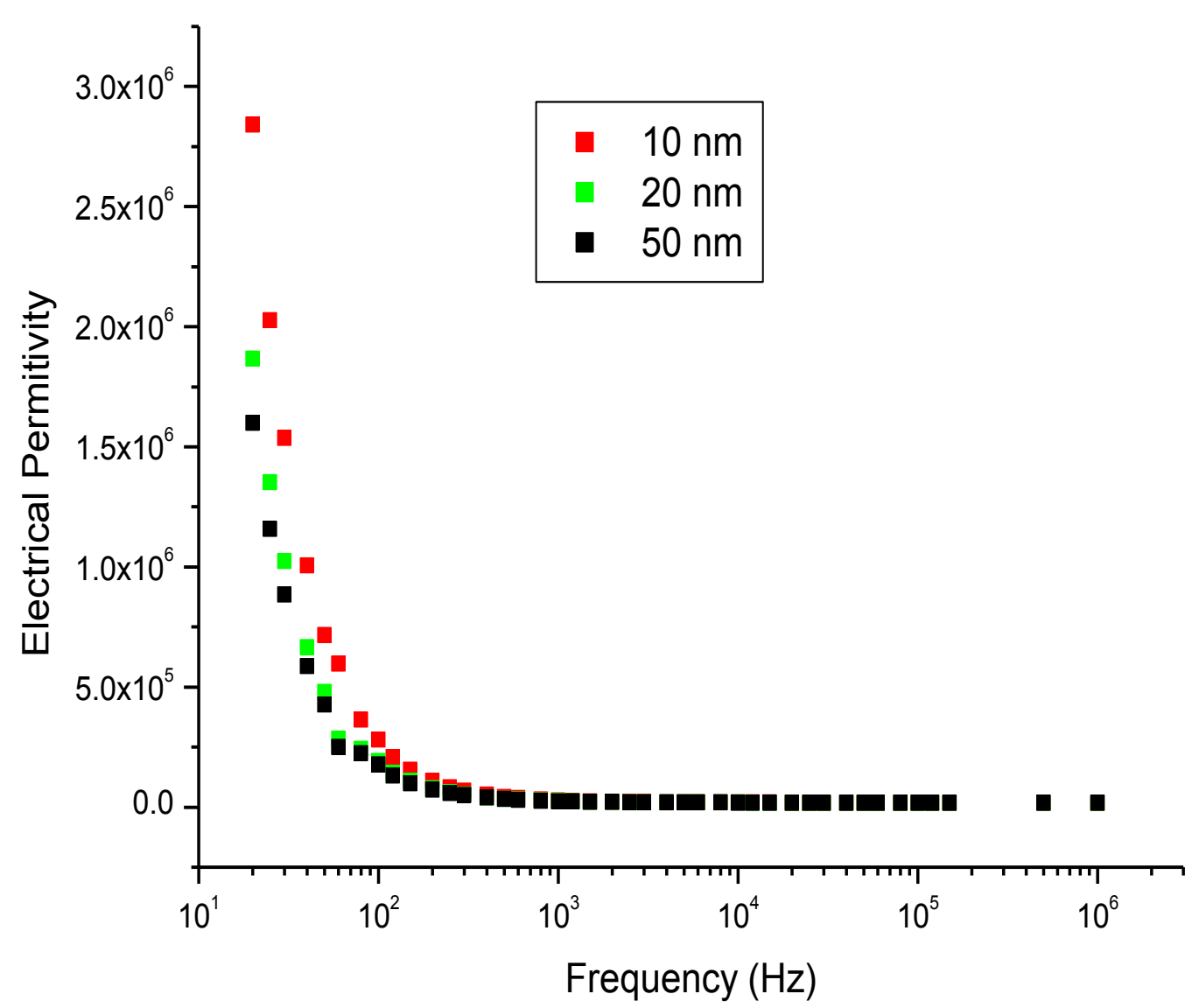

Figure 7 relative permittivity $\varepsilon^{\prime}$ as function of the applied frequency in the range of $20 \mathrm{~Hz}$ to $1 \mathrm{MHz}$ for 10,20 and $50 \mathrm{~nm}$ gold nanoparticles. 


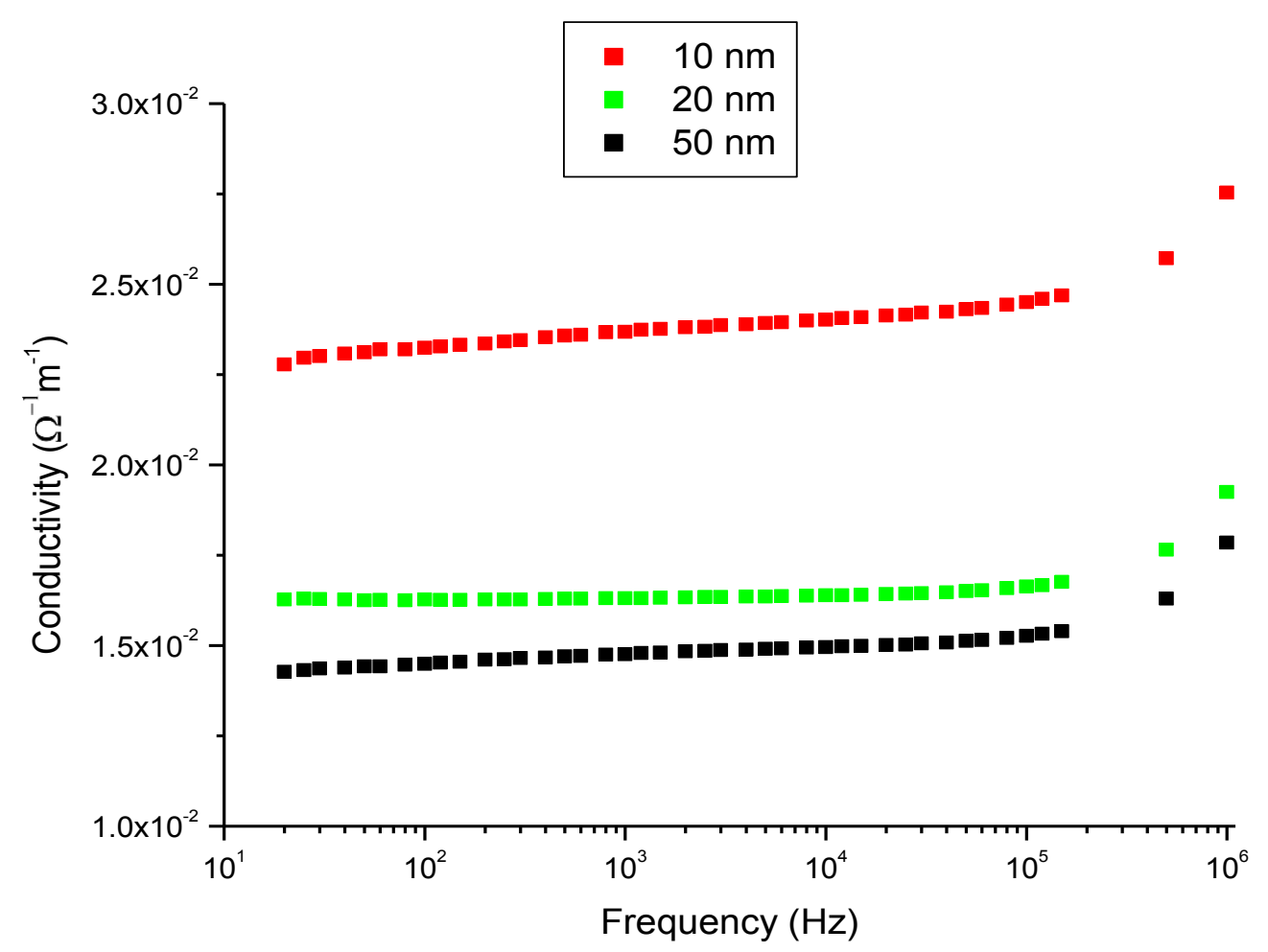

Figure 8 electrical conductivity $(\sigma)$ as function of the applied frequency in the range of $20 \mathrm{~Hz}$ to $1 \mathrm{MHz}$ for 10,20 and $50 \mathrm{~nm}$ gold nanoparticles.

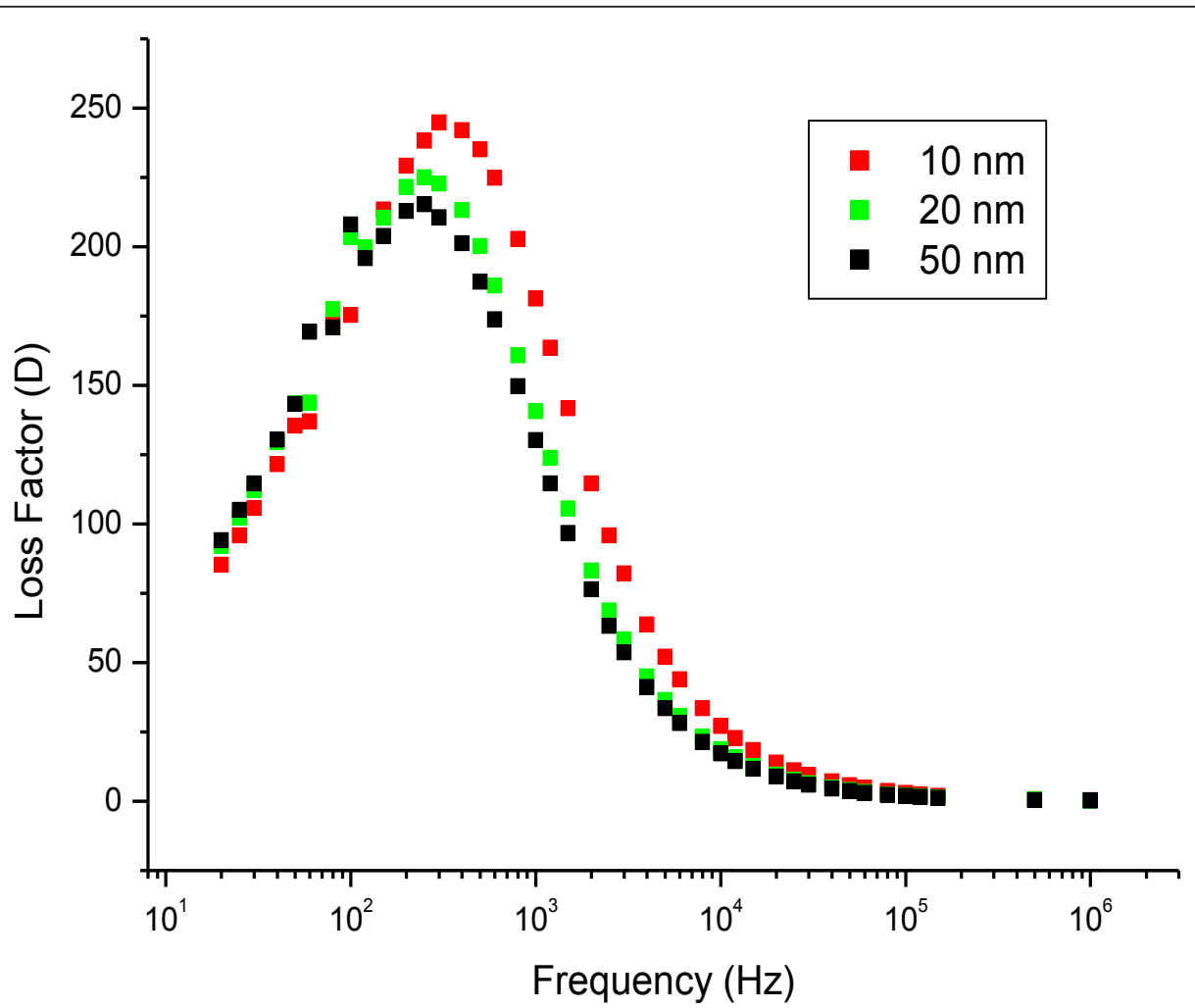

Figure 9 the variation of loss factor $(\tan \delta)$ with the applied frequency in the range of $20 \mathrm{~Hz}$ to $1 \mathrm{MHz}$ for 10,20 and $50 \mathrm{~nm}$ gold nanoparticles. 
attributed to the increase in the localized charges distribution within the medium which was confirmed from the conductivity data (Figure 9).

Further studies are required to be done after the administration of GNPs through different routes in the rats in vivo.

\section{Conclusions}

The 10, 20 and $50 \mathrm{~nm}$ GNPs were used in the present study. The rheological and the dielectric properties of these GNPs were investigated.

Our findings revealed that the increase in viscosity was GNPs size dependent. The shear stress and shear rate of GNPs have shown linear relationship and exhibited Newtonian behaviour. The GNPs with larger size $(50 \mathrm{~nm})$ exhibited higher viscosity values than those with smaller particle sizes (10 and $20 \mathrm{~nm}$ ).

Viscosity of GNPs decreased with increasing the temperature for all the examined GNPs sizes. The values of the flow behaviour index (n) were $\leq 1$ for all examined GNPs sizes.

The dielectric data indicated that GNPs have strong dielectric dispersion in the frequency range of $20 \mathrm{~Hz}-100$ $\mathrm{kHz}$ which was particles size dependent. Moreover, the conductivity increased with increasing the size of GNPs.

The relaxation time decreased with increasing the GNP size which may be attributed to increase in the localized charge distribution within the medium confirmed by the conductivity data.

\footnotetext{
Acknowledgements

The authors are very grateful to National Plan of Science and Technology (NPST). This research was financially supported by the National Science and Technology Innovation Plan (NSTIP), Research No. 08-ADV206-02 and Research No. 09-NAN670-02, College of Science, King Saud University, Saudi Arabia.
}

\section{Author details}

'Department of Physics and Astronomy, College of Science, King Saud University, P.O. 2455, Riyadth 11451, Saudi Arabia. ${ }^{2}$ Biophysics Department, Faculty of Science, Cairo University, 12613 Giza, Egypt.

\section{Authors' contributions}

MAKA, MMM and MMG have analyzed data, interpreted and written the final draft of this manuscript. The animal model used in this study was obtained from the Laboratory Animal Center (College of Pharmacy, King Saud University, Saudi Arabia). MAKA has conceived the study and its design and obtained research grants for this study. The authors have read and approved the final manuscript.

\section{Competing interests}

The authors declare that they have no competing interests.

Received: 6 November 2011 Accepted: 11 November 2011 Published: 11 November 2011

\section{References}

1. Brust M, Bethell D, Kiely CJ, Schiffrin DJ: Self-assembled gold nanoparticle thin films with non-metallic optical and electronic properties. Langmuir 1998, 14(19):5425-5429.
2. Li H, Jiang L: Polymer light-emitting diodes with spin-coated poly.(3,4ethylenedioxythiophene)- polystyrenesulfonate as transparent anode. Prog Chem 1997, 9:397.

3. Schmid G: Large clusters and colloids. Metals in the embryonic state. Chem Rev 1992, 92:1709.

4. Brust M, Fink J, Bethell D, Schiffrin DJ, Kiely C: Synthesis and Reactions of Functionalised Gold Nanoparticles. J Chem Soc, Chem Comm 1995, 1655-1656.

5. Collier CP, Saykally RJ, Shiang JJ, Henrichs SE, Heath JR: Reversible Tuning of Silver Quantum Dot Monolayers Through the Metal-Insulator Transition. Science 1997, 277:1978.

6. Sun SH, Murray CB, Weller D, Folks L, Moster AJ: Monodisperse FePt nanoparticles and ferromagnetic FePt nanocrystal superlattices. Science 2000, 287:1989.

7. Lyon LA, Pena Dj, Natan MJ: Surface Plasmon Resonance of Au ColloidModified Au Films: Particle Size Dependence. J Phys Chem B 1999, 103:5826.

8. Link S, El-sayed MA: Spectral Properties and Relaxation Dynamics of Surface Plasmon Electronic Oscillations in Gold and Silver Nanodots and Nanorods. J Phys Chem B 1999, 103:4212.

9. Chen CK, Hemz II, Ricard D, Shen YR: Surface-enhanced second-harmonic generation and Raman scattering. Phys Rev B 1983, 27:1965.

10. Kreibig U, Vollmer M: Optical Properties of Metal Clusters. Springer, Berlin; 1995.

11. Mirkin CA, Ratner MA: Controlled synthesis and quantum-size effect in gold-coated nanoparticles. Annu Rev Phys Chem 1997, 101:1593.

12. Rampi MA, Schueller OJA, Whitesides GM: Alkanethiol Self-Assembled Monolayers as the Dielectric of Capacitors with Nanoscale Thickness. Appl Phys Lett 1998, 72:1781.

13. Klein $\mathrm{DL}$, Roth $\mathrm{R}$, Lim AKL, Alivisatos AP, McEuen PL: A single-electron transistor made from a cadmium selenide nanocrystal. Nature 1997 389:699.

14. Bumm LA, Arnold JJ, Dunbar TD, ALLara DL, Weiss PS: Electron Transfer through Organic Molecules. Science 1996, 271:1705.

15. Ghosh SK, Kundu S, Mandal M, Nath S, Pal T: Studies on the evolution of silver nanoparticles in micelle by UV-photoactivation. J Nanopart Res 2003, 5:577.

16. Mirkin CA, Letsinger RL, Mucic RC, Storhoff JJ: A DNA based method for assembling nanoparticles. Nature 1996, 382:607-609.

17. Huber M, Wei TF, Muller UR, Lefebvre PA, Marla SS, Bao YP: Gold nanoparticle probe-based gene expression analysis with unamplified total human RNA. Nucleic Acids Res 2004, 32:e137-e145.

18. Ow Sullivan MM, Green JJ, Przybycien TM: Development of a novel gene delivery scaffold utilizing colloidal gold-polyethylenimine conjugates for DNA condensation. Gene Therapy 2003, 22:1882-1890.

19. Sandhu KK, McIntosh CM, Simard JM, Smith SW, Rotello VM: Gold nanoparticle-mediated transfection of mammalian cells. Bioconjug Chem 2002, 1:3-6.

20. Niidome T, Nakashima K, Takahashi H, Niidome Y: Preparation of primary amine-modified gold nanoparticles and their transfection ability into cultivated cells. Chem Commun (Camb) 2004, 17:1978-1979.

21. Kawano T, Yamagata M, Takahashi H, Niidome Y, Yamada S, Katayama Y, Niidome T: Stabilizing of plasmid DNA in vivo by PEG-modified cationic gold nanoparticles and the gene expression assisted with electrical pulses. J Control Release 2006, 111:382-389.

22. El-Sayed $I H$, Huang $X$, El-Sayed MA: Selective laser photothermal therapy of epithelial carcinoma using anti-EGFRantibody conjugated gold nanoparticles. Cancer Lett 2006, 239:129-135.

23. Sperling RA, Gil PR, Zhang F, Zanella M, Parak WJ: Biological applications of gold nanoparticles. Chem Soc Rev 2008, 37:1896-1908.

24. Tokonami S, Shiigi H, Nagaoka T: Preparation of Nanogapped Gold Nanoparticle Array for DNA Detection. Electroanalysis 2008, 20:355-360.

25. Huang $X$, Jain PK, El-Sayed IH, El-Sayed MA: Special Focus: Nanoparticles for Cancer Diagnosis \& Therapeutics - Review; Gold nanoparticles: interesting optical properties and recent applications in cancer diagnostics and therapy. Nanomedicine 2007, 2:681-693.

26. Zhang D, Chava S, Berven C, Lee SK, Devitt R, Katkanant V: Experimental study of electrical properties of $\mathrm{ZnO}$ nanowire random networks for gas sensing and electronic devices. Appl Phys A 2010, 100:145-150.

27. Scaldaferri1 R, Salzillo G, Pepe GP, Barra M, Cassinese A, Pagliarulo V, Borriello A, Fusco L: Influence of fillers concentration on electrical 
properties of polystyrene matrix doped by gold nanoparticles and $8 \mathrm{HQ}$. Eur Phys J B 2009, 72:113-118.

28. Dutta A, Tarbell JM: Influence of non-Newtonian behavior of blood on flow in an elastic artery model. J Biomech Eng 1996, 118:111-119.

29. Steffe J: Rheological methods in food process engineering. Freeman Press, Mitchigan State University, USA; 2 1996, 21.

30. Mady MM, Darwish M, Khalil S, Khalil W: Biophysical studies on chitosancoated liposomes. Eur Biophysics J 2009, 38:1127-1133.

doi:10.1186/1476-511X-10-208

Cite this article as: Abdelhalim et al:: Rheological and dielectric properties of different gold nanoparticle sizes. Lipids in Health and Disease 2011 10:208.

Submit your next manuscript to BioMed Central and take full advantage of:

- Convenient online submission

- Thorough peer review

- No space constraints or color figure charges

- Immediate publication on acceptance

- Inclusion in PubMed, CAS, Scopus and Google Scholar

- Research which is freely available for redistribution

Submit your manuscript at www.biomedcentral.com/submit 